\title{
Synthesis and evaluation of new guanidine-thiourea organocatalyst for the nitro-Michael reaction: Theo- retical studies on mechanism and enantioselectivity
}

\author{
Tatyana E. Shubina*1, Matthias Freund ${ }^{2}$, Sebastian Schenker², \\ Timothy Clark ${ }^{* 1}$ and Svetlana B. Tsogoeva ${ }^{* 2}$
}

\section{Full Research Paper}

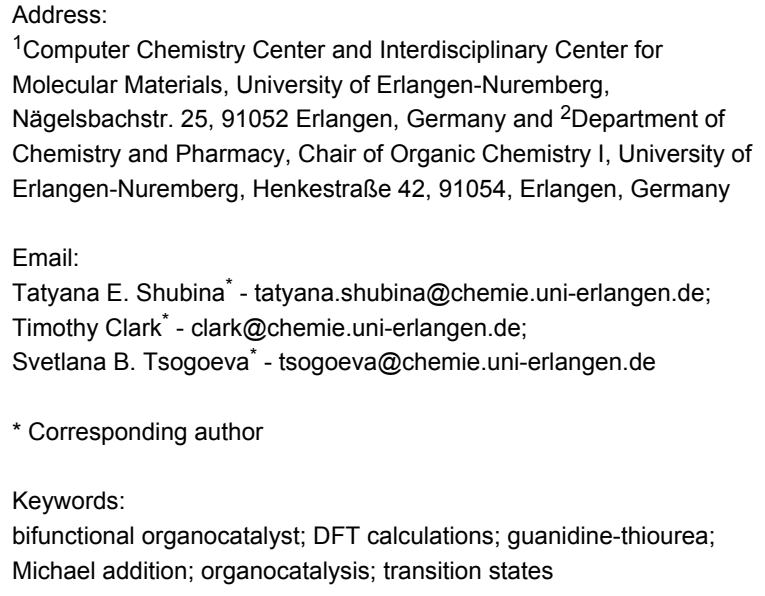

\begin{abstract}
\section{Introduction}

In recent years bifunctional compounds have found frequent applications as organocatalysts in modern synthetic organic chemistry [1-8]. Over the past decade, different catalytic methodologies have been reported that use chiral thiourea-based bifunctional molecules [9-13]. In particular, remarkable progress has been made in the development of secondary and tertiary amine-thiourea bifunctional organocatalysts for a great number of useful transformations [14-35].
\end{abstract}

A new guanidine-thiourea organocatalyst has been developed and applied as bifunctional organocatalyst in the Michael addition reaction of diethyl malonate to trans- $\beta$-nitrostyrene. Extensive DFT calculations, including solvent effects and dispersion corrections, as well as ab initio calculations provide a plausible description of the reaction mechanism.

Recently, the Tsogoeva group and that of Jacobsen reported the first successful application of primary amine-thiourea organocatalysts with the synchronous dual activation of a nucleophile and an electrophile in nitro-Michael addition reactions [36-42]. Bifunctional organocatalysts that contain both a thiourea moiety and an imidazole group $[43,44]$ on a chiral scaffold, as asymmetric catalysts in the addition of acetone to trans- $\beta$-nitrostyrene, have also been reported [44-47]. 
Since guanidines [48] are stronger bases than amines and/or imidazole, we were interested in exploring whether guanidinethiourea organocatalysts would perform as well as or even better than amine-thioureas and imidazole-thioureas. Generally, guanidines are well-known basic catalysts in organic synthesis, but only scattered examples of chiral guanidines as organocatalysts are known [49]. Indeed, only one guanidine-thiourea organocatalyst has been published up until now [50-53]. This encouraged us to synthesize and investigate the potential of new guanidine-thiourea 7 as organocatalyst for the nitro-Michael addition reactions. Here we report the first results of our investigations, accompanied by quantum-chemical calculations on the mechanism and the observed stereoselectivity.

\section{Results and Discussion Synthesis and application of new guanidine- thiourea catalyst 7}

The syntheses of new guanidine-thiourea compound 7 was accomplished by known methods [36,38,40,54-56] as summarised in Scheme 1. (S,S)-1,2-Diaminocyclohexane (1) and (R)-1phenylethyl isothiocyanate (2) were employed for the synthesis of primary amine-thiourea $3[36,38,40,54]$. Subsequent treatment of 3 with a guanidinylation reagent, $N, N^{\prime}$-di-Boc- $N N^{\prime \prime}$ triflylguanidine (4) [54,55], gave the intermediate 5 in $98 \%$ yield. The next step involved cleavage of the tert-butyl groups with trifluoroacetic acid (TFA) to give the corresponding salt 6 in $85 \%$ yield. Finally, guanidinium salt neutralisation with Amberlyst A26 ( $\mathrm{OH}^{-}$form) [56], filtration and evaporation afforded the guanidine-thiourea 7 in high yield and purity.
This compound was then examined for its ability to mediate the enantioselective $\mathrm{C}-\mathrm{C}$ bond-formation reactions. As an initial model transformation we studied the Henry reaction of 3-phenylpropionaldehyde (8) with nitromethane (9) in the presence of $10 \mathrm{~mol} \%$ of 7 , with the reaction proceeding for $48 \mathrm{~h}$ at room temperature in toluene. However, guanidine-thiourea 7 gave the product $\mathbf{1 0}$ only in racemic form and in moderate yield (62\%, Scheme 2).

The Michael additions of 2,4-pentanedione and diethylmalonate to trans- $\beta$-nitrostyrene were further explored (Scheme 3). The use of guanidine-thiourea 7 at $20 \mathrm{~mol} \%$ in toluene at room temperature resulted in the formation of the corresponding products $\mathbf{1 3}$ and $\mathbf{1 5}$ in moderate yields and low enantioselectivities, i.e., $54 \%$, 25\% ee for $\mathbf{1 3}$ (Scheme 3) and $66 \%, 5 \%$ ee for 15 (Scheme 3, Table 1, entry 1). Interestingly, while catalyst 7 provides the product 13 in 54\% yield after 120 $\mathrm{h}$, the same catalyst produces the Michael product 15 with $66 \%$ yield in only $2 \mathrm{~h}$. We therefore decided to study the solvent effects on the reaction outcome in the nitro-Michael reaction of diethylmalonate with trans- $\beta$-nitrostyrene further. The results are shown in Table 1. Whereas Michael reactions performed in dichloromethane and ethyl acetate showed better results in terms of yields, compared to the results obtained in toluene (Table 1, entries 2 and 3 versus entry 1), reactions in ether and ethanol gave the adduct with lower yields (Table 1, entries 4 and 5). Notably, the highest yield (96\%, Table 1, entry 6) was observed in THF. However, the Michael product was nearly racemic in all runs, indicating that the influence of chirality of

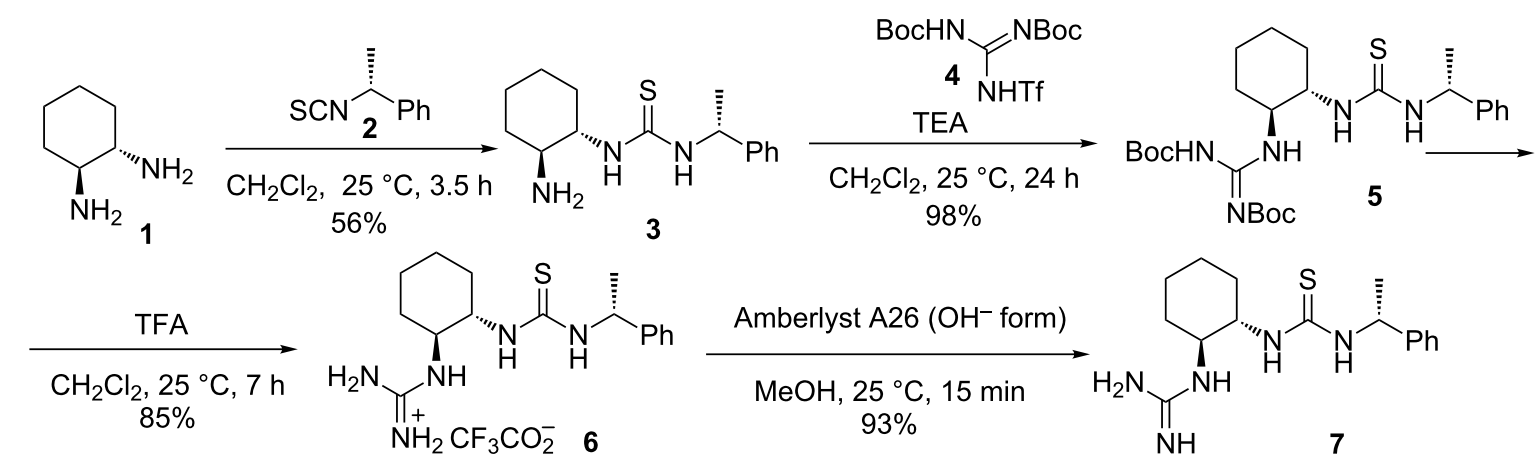

Scheme 1: Synthesis of guanidine-thiourea organocatalyst 7.

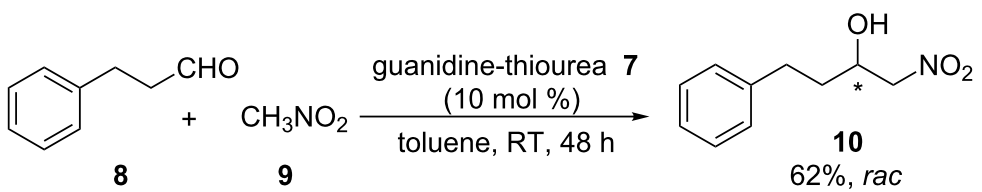

Scheme 2: Henry reaction of 3-phenylpropionaldehyde (8) with nitromethane (9). 

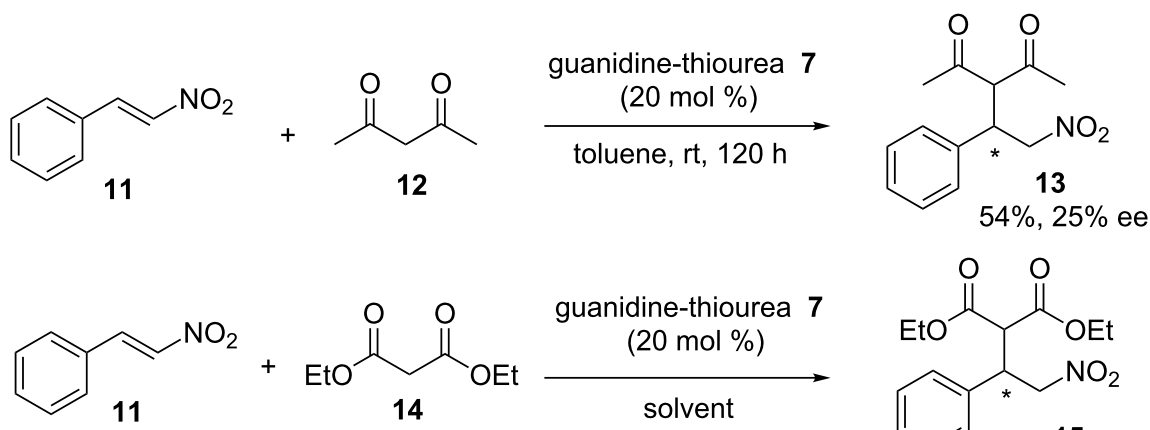<smiles>CCOC(=O)C(C(=O)OCC)C(=C[N+](=O)[O-])c1ccccc1</smiles>

Scheme 3: Michael addition of (12) and (14) to trans- $\beta-$-nitrostyrene (11).

the catalyst was minimal in all of the solvents screened. We expected that the resulting ee value would be higher at a lower temperature. However, carrying out the reaction for $24 \mathrm{~h}$ in $\mathrm{THF}$ at $-78{ }^{\circ} \mathrm{C}$ gave again the racemic product in $78 \%$ yield. Hence, yield rather than ee value is influenced here by the reaction temperature. In order to explain the enantioselectivities observed, as well as to refine the catalyst design, or possibly get ideas that can be transferred to other systems, we decided to carry out a computational investigation of this guanidinethiourea catalysed nitro-Michael reaction employing density functional calculations.

Table 1: Screening of solvents for the guanidine-thiourea 7 catalysed nitro-Michael addition of diethylmalonate (14) to trans- $\beta$-nitrostyrene (11) (Scheme 3)

\begin{tabular}{lllll} 
entry & temperature & solvent & \multicolumn{2}{l}{ reaction time $[\mathrm{h}]$} \\
\hline 1 & $\mathrm{rt}$ & toluene & 2 & 66 \\
2 & $\mathrm{rt}$ & $\mathrm{CH}_{2} \mathrm{Cl}_{2}$ & 2 & 81 \\
3 & $\mathrm{rt}$ & $\mathrm{EtOAC}^{\mathrm{a}}$ & 2 & 83 \\
4 & $\mathrm{rt}$ & $\mathrm{Et}_{2} \mathrm{O}$ & 2 & 42 \\
5 & $\mathrm{rt}$ & $\mathrm{EtOH}$ & 2 & 56 \\
6 & $\mathrm{rt}$ & THF & 2 & 96 \\
7 & $-78{ }^{\circ} \mathrm{C}$ & THF & 24 & 78 \\
\hline
\end{tabular}

aYield of isolated product after column chromatography on $\mathrm{SiO}_{2}$.

\section{Theoretical studies: DFT calculations}

The main goal of our calculations was to gain insight into the mechanism of the nitro-Michael addition of diethyl malonate (14) to nitrostyrene (11) and to find a plausible explanation as to why the enantioselectivity of this reaction is low. As a first step, we explored the conformational flexibility of the catalyst 7 itself. Pápai and co-workers [57] studied a similar dimethylaminothiourea catalyst and found that their system cannot be treated as conformationally rigid. Thus, a full conformational search of 7 was performed at the AM1 level by using the TORQUE algorithm within the VAMP program [58]. Based on the clustered semiempirical results, the four most stable structures were selected for the further optimization at the B3PW91/ 6-31G(d) level. Conformer 7a is the only one with two hydrogen bonds between a nitrogen atom in the guanidine moiety and hydrogen atoms from the thiourea fragment. While inclusion of the solvent effect (DFT-PCM) gives a preference of $3.1 \mathrm{kcal} \cdot \mathrm{mol}^{-1}$ for $\mathbf{7 b}$ over $\mathbf{7 a}$ (Figure 1 ), gas-phase DFT, MP2 and DFT-D with van der Waals correction predict 7a to be more stable than $7 \mathbf{b}$ by between 1.8 and $7.4 \mathrm{kcal} \cdot \mathrm{mol}^{-1}$ (Figure 1). The MP2 and DFT-D energies agree very well. The two other conformers, $\mathbf{7 c}$ and $\mathbf{7 d}$, are less stable than $\mathbf{7 a} / \mathbf{7} \mathbf{b}$ at all levels employed and were therefore not considered for the further studies.

A similar Michael reaction of 1,3-dicarbonyl compounds with nitroolefins has been studied in some detail before [57,59]. It is generally proposed that the reaction proceeds first by deprotonation of the acidic proton of malonate $\mathbf{1 4}$ followed by formation of a complex between 7 and 14. Formation of Complex1 between catalyst 7 and malonate $\mathbf{1 4}$ is exothermic $(-6.5,-15.0$ and $-16.6 \mathrm{kcal} \cdot \mathrm{mol}^{-1}$ B3PW91/6-31G(d), MP2 and DFT-D, respectively, Scheme 4). Two energetically almost equivalent complexes Complex1 and Complex2 are connected by the $\mathrm{H}$-abstraction transition state with a rather low activation barrier of $4.4 \mathrm{kcal} \cdot \mathrm{mol}^{-1}$ at the B3PW91/6-31G(d) level. Inclusion of PCM, MP2 and DFT-D corrections increases the activation barrier to $12.2,9.4$ and $8.0 \mathrm{kcal} \cdot \mathrm{mol}^{-1}$, in the DFT-PCM, MP2 and DFT-D results, respectively. We were also able to find a second complex Complex2a, which is less stable than Complex2 by up to $22.9 \mathrm{kcal} \cdot \mathrm{mol}^{-1}$ (MP2, Scheme 4). Again, gasphase DFT, MP and DFT-D results follow the same trend, while inclusion of the solvent effect makes Complex2a $0.4 \mathrm{kcal} \cdot \mathrm{mol}^{-1}$ more stable than Complex2 (Scheme 4). In this complex, malonate $\mathbf{1 4}$ is coordinated only to the guanidine moiety. 

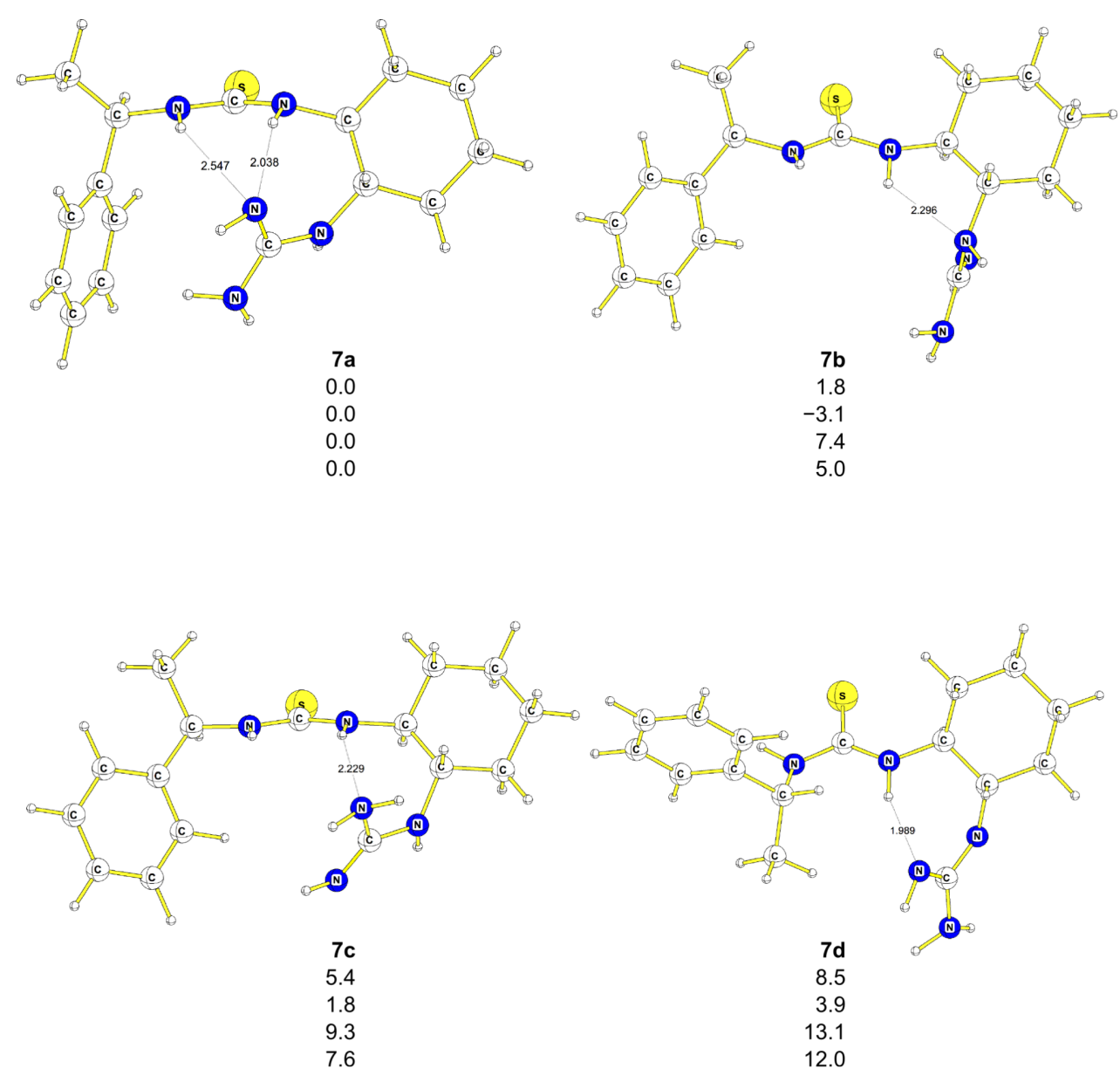

Figure 1: Optimized geometries of four conformers of catalyst 7. Energies are in kcal-mol ${ }^{-1}$, B3PW91/6-31G(d) (first entry), DFT-PCM (second entry), MP2/6-311++G(d,p)// B3PW91/6-31G(d) (third entry), DFT-D (fourth entry). Bond lengths are in $\AA$.

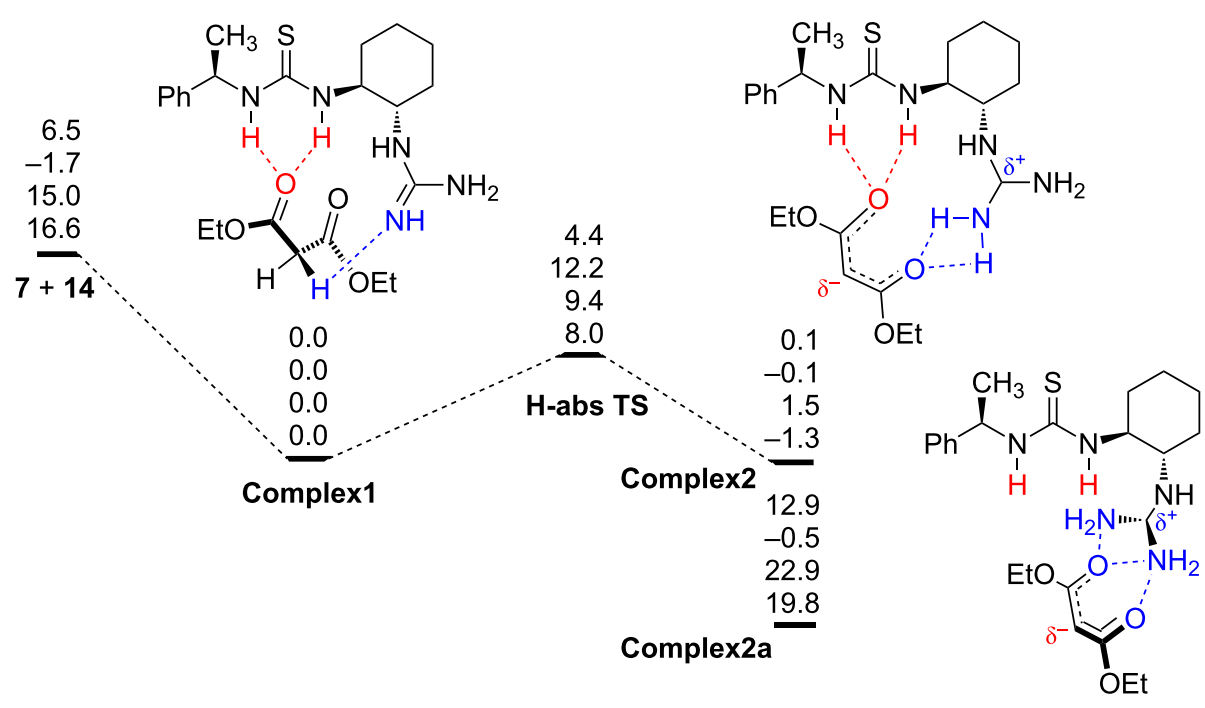

Scheme 4: Energy profile for the first step of the reaction between catalyst 7 and malonate 14. Energies are in $\mathrm{kcal}^{\mathrm{m}} \cdot \mathrm{mol}^{-1}$, B3PW91/6-31G(d) (first entry), DFT-PCM (second entry), MP2/6-311++G(d,p)//B3PW91/6-31G(d) (third entry), DFT-D (fourth entry). 
Since catalyst 7 has a certain degree of conformational flexibility, one can expect various complexes between the catalyst 7 and nitrostyrene (11) to exist. We were able to locate five complexes (Figure 2) that differ in energy by up to $10.3 \mathrm{kcal} \cdot \mathrm{mol}^{-1}\left\{5.0 \mathrm{kcal} \cdot \mathrm{mol}^{-1}\right.$ (DFT-PCM), $22.6 \mathrm{kcal} \cdot \mathrm{mol}^{-1}$, (MP2), $18.5 \mathrm{kcal} \cdot \mathrm{mol}^{-1}$, (DFT-D) $\}$.

It is interesting to note that nitrostyrene can coordinate not only to the thiourea moiety, as originally suggested by Takemoto and co-workers [22], but also to the amino group (as pointed out by Pápai and co-workers [57]) or both. The ternary complex Init10 between catalyst 7, malonate $\mathbf{1 4}$ and nitrostyrene (11) can be formed via two routes (Scheme 5): Formation of Complex1, activation of catalyst and $\mathrm{H}$-transfer followed by addition of nitrostyrene (11) to Complex 2 or addition of malonate $\mathbf{1 4}$ to the complex CatN1 followed by catalyst activation and H-transfer. The thermodynamics of both routes are comparable at all levels.
Once ternary complex Init10 is formed, there are few $\mathrm{C}-\mathrm{C}$ bond-forming pathways.

Based on the extensive conformational search, we were able to find eleven competing transition states (Figure 3 and Figure 4), six of which lead to $R$ products (TS1, TS3, TS7, TS9, TS11, TS12), and five of which (TS2, TS5, TS6, TS8, TS10) lead to $S$ products; the corresponding initial and final complexes were also located. All but one (TS6 $S$ ) transition state for the $S$ enantiomer were found to lay lower on the potential-energy surface (PES), at all levels employed, compared to the corresponding transition states that lead to the $R$ product. The activation barriers vary between $+7.3 \mathrm{kcal} \cdot \mathrm{mol}^{-1}\left(+7.5 \mathrm{kcal} \cdot \mathrm{mol}^{-1} \mathrm{DFT}\right.$ PCM, TS8 $S)$ and $+14.1 \mathrm{kcal} \cdot \mathrm{mol}^{-1}\left(+14.5 \mathrm{kcal} \cdot \mathrm{mol}^{-1}\right.$ DFTPCM, TS7 R). DFT-D and MP2/6-311++G(d,p)//6-31G(d) results support the same trend, although the absolute values of the activation energies are much lower and in some cases even

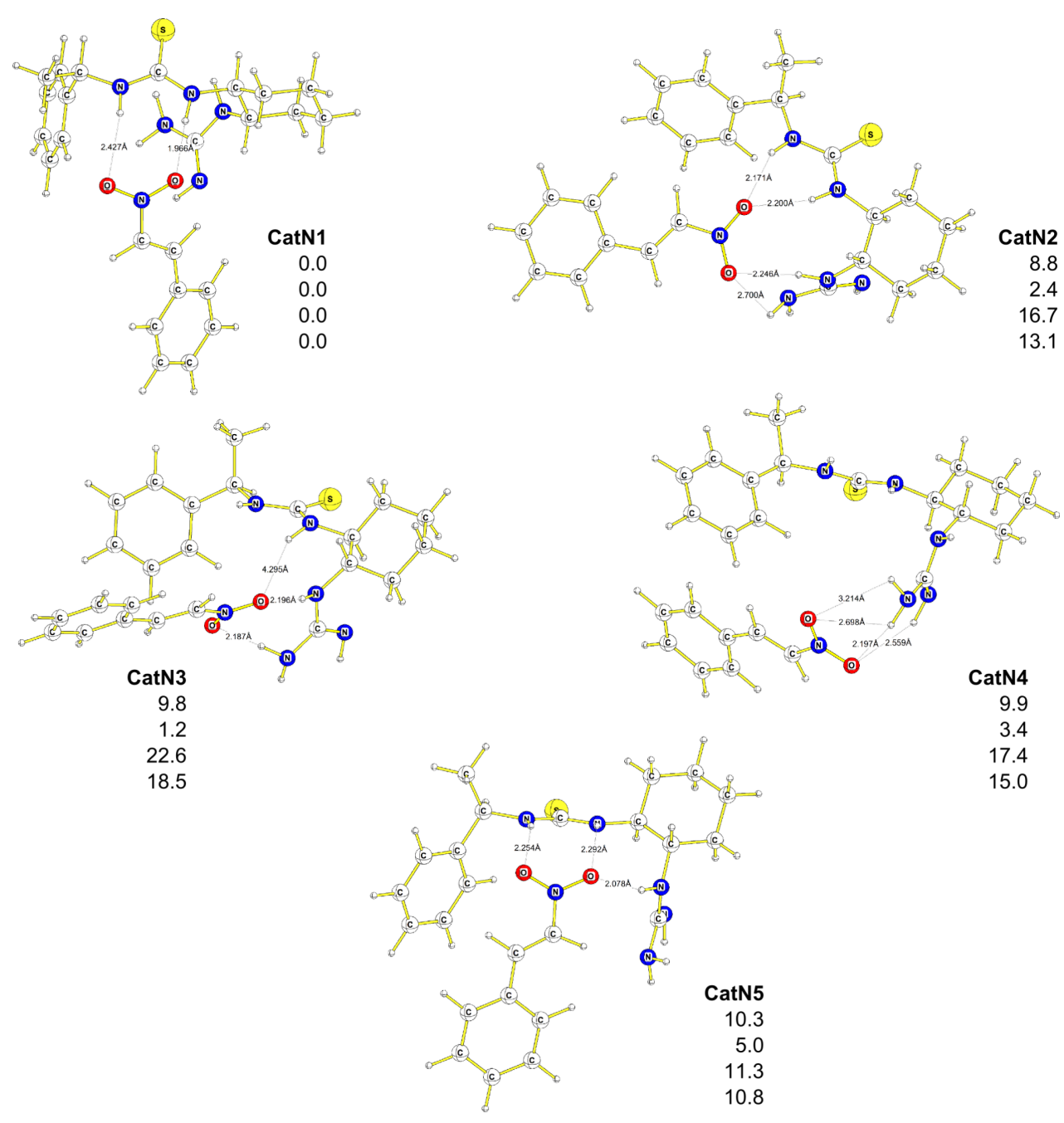

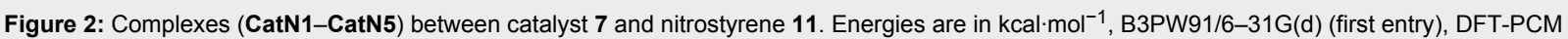
(second entry), MP2/6-311++G(d,p)// B3PW91/6-31G(d) (third entry), DFT-D (fourth entry). Bond lengths are in $\AA$. 


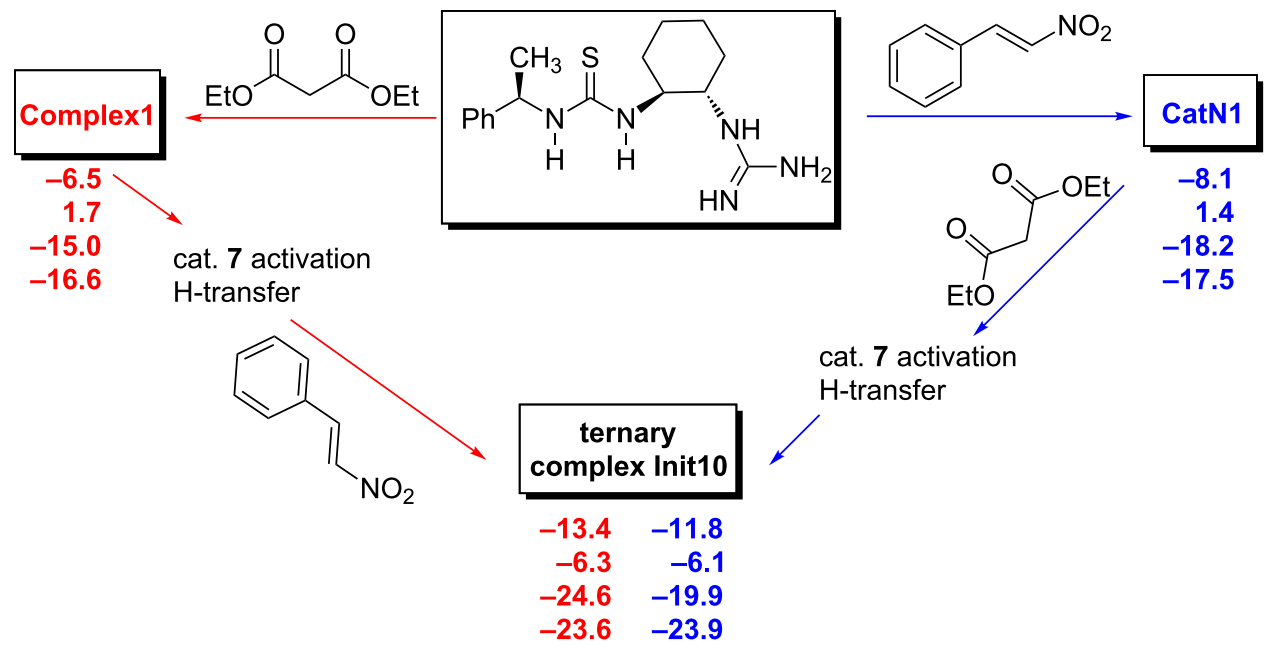

Scheme 5: Two possible routes for ternary complex formation. Energies are in kcal-mol ${ }^{-1}$, B3PW91/6-31G(d) (first entry), DFT-PCM (second entry), MP2/6-311++G(d,p)//B3PW91/6-31G(d) (third entry), DFT-D (fourth entry).

negative activation barriers were found (Figure 3 and Figure 4, Table 2). Relatively low activation barriers could explain the poor selectivity observed experimentally for this reaction, i.e., catalyst $\mathbf{7}$ is too active. The computed ee based on the theory of the activated complex (see Supporting Information File 1) give values between $43 \%$ and $99 \%$, significantly higher than those observed experimentally. Also, at least six initial complexes (INIT7-INIT12) can interconvert, as the energy difference between them ranges from $0.7 \mathrm{kcal} \cdot \mathrm{mol}^{-1}$ to $4.3 \mathrm{kcal} \cdot \mathrm{mol}^{-1}$ (B3PW91/6-31G(d), Table 2).
In such a case (i.e., low barriers that result in thermodynamic control of the reaction products), the course of the reaction will be determined by the stability of the final $R$ and $S$ products. The most stable conformations of the final $R$ and $S$ complexes are essentially equally stable (Table 2 ). Thus, the experimentally observed low ee can be explained by the high catalytic activity of 7. To lower its activity and to increase the selectivity of the reaction one can modify catalyst 7 , either by modifying a substituent, e.g., by introducing the bulky groups $(t-\mathrm{Bu})$ into the phenyl ring, or by modifying the guanidine moiety. Preliminary

Table 2: Computed energy difference between initial and final complexes and activation barriers with respect to the Init10 complex. Energies are in $\mathrm{kcal} \cdot \mathrm{mol}^{-1}, \mathrm{~B} 3 \mathrm{PW} 91 / 6-31 \mathrm{G}(\mathrm{d}),(\mathrm{DFT}-\mathrm{PCM}),\{\mathrm{MP} 2 / 6-311++\mathrm{G}(\mathrm{d}, \mathrm{p}) / / \mathrm{B} 3 \mathrm{PW} 91 / 6-31 \mathrm{G}(\mathrm{d})\}$ and [DFT-D].

\begin{tabular}{llll} 
& INIT & TS & FIN \\
\hline $\mathbf{1} R$ & $10.7(10.9)\{8.8\}[10.4]$ & $12.2(13.1)\{7.9\}[10.5]$ & $1.7(-1.0)\{-10.6\}[-2.5]$ \\
$\mathbf{5} \mathbf{S}$ & $8.9(7.3)\{9.7\}[10.1]$ & $10.3(9.5)\{7.2\}[8.3]$ & $-0.2(-2.9)\{-12.8\}[-4.9]$ \\
$\mathbf{2} \mathbf{S}$ & $8.5(8.7)\{7.8\}[10.5]$ & $13.8(13.3)\{8.9\}[11.6]$ & $3.0(1.6)\{-9.0\}[-3.3]$ \\
$\mathbf{3} \boldsymbol{R}$ & $7.0(5.6)\{9.5\}[10.8]$ & $10.0(10.1)\{5.6\}[8.7]$ & $1.8(-0.7)\{-11.2\}[-3.7]$ \\
$\mathbf{6} \mathbf{S}$ & $7.5(6.4)\{8.4\}[9.5]$ & $10.2(10.3)\{5.9\}[9.3]$ & $1.9(0.1)\{-12.2\}[-5.0]$ \\
$\mathbf{7} \mathbf{R}$ & $4.3(4.9)\{3.9\}[4.7]$ & $14.1(14.5)\{3.0\}[8.0]$ & $5.4(3.9)\{-11.9\}[-4.6]$ \\
$\mathbf{8} \mathbf{S}$ & $1.0(1.5)\{-0.4\}[0.7]$ & $7.4(8.1)\{-1.6\}[1.1]$ & $-5.7(-6.8)\{-21.3\}[-13.8]$ \\
$\mathbf{9} \boldsymbol{R}$ & $1.1(0.9)\{0.5\}[1.6]$ & $8.1(8.7)\{3.0\}[4.8]$ & $-5.9(-6.6)\{-20.5\}[-13.2]$ \\
$\mathbf{1 0} \mathbf{S}$ & $0.0(0.0)\{0.0\}[0.0]$ & $8.1(8.4)\{-0.8\}[2.7]$ & $-4.5(-5.2)\{-14.1\}[-8.7]$ \\
$\mathbf{1 1} \boldsymbol{R}$ & $0.7(1.4)\{0.4\}[1.4]$ & $9.0(9.7)\{1.0\}[4.1]$ & $-1.4(-3.4)\{-16.8\}[-9.4]$ \\
$\mathbf{1 2} \boldsymbol{R}$ & $1.3(1.0)\{-0.2\}[1.2]$ & $7.3(7.5)\{-3.2\}[0.6]$ & $-5.9(-6.6)\{-20.5\}[-13.2]$
\end{tabular}



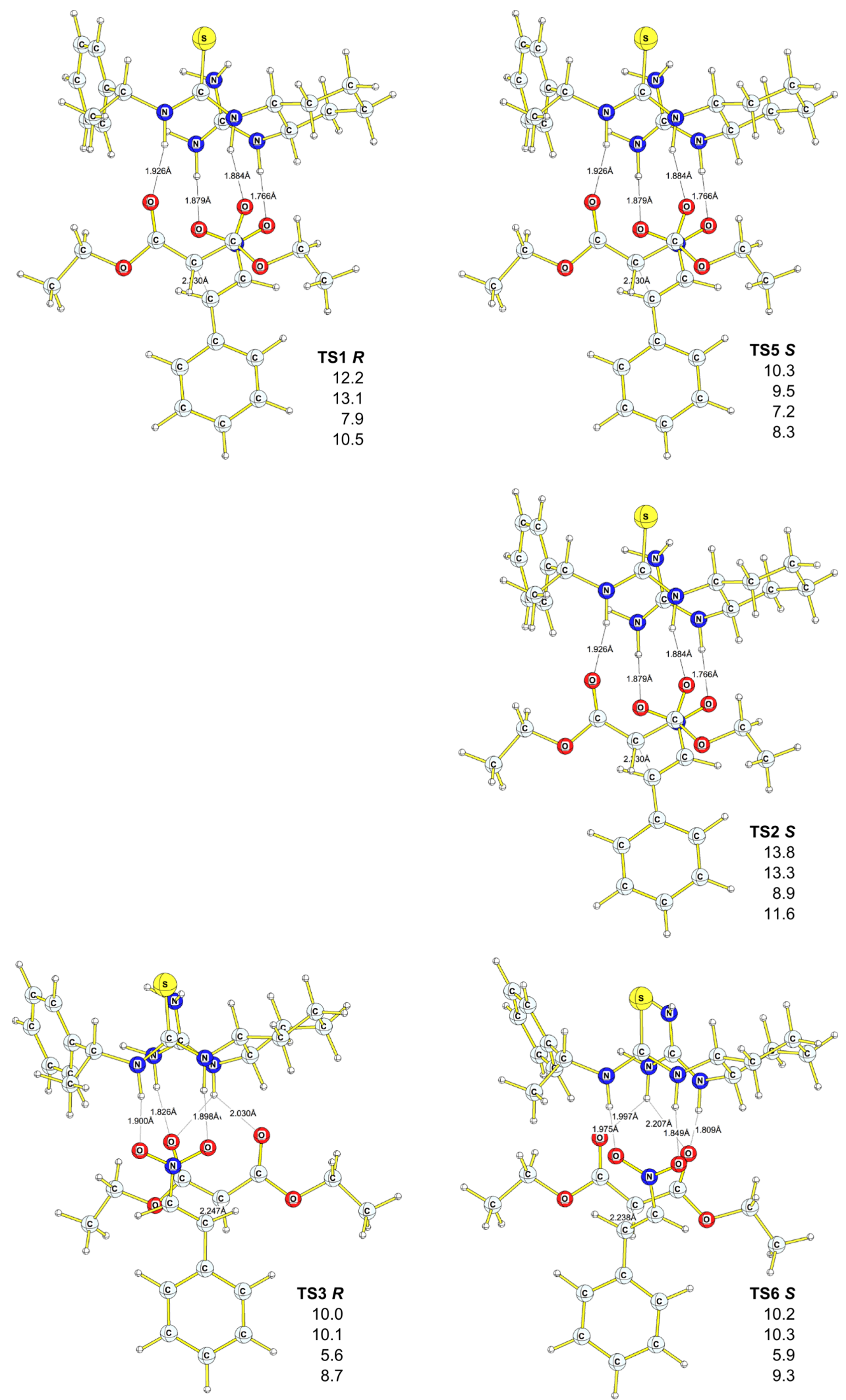

Figure 3: Geometries of transition states for $R$ and $S$ products. Relative energies (with respect to Init10) are in $\mathrm{kcal}^{\mathrm{k}} \cdot \mathrm{mol}^{-1}$, B3PW91/6-31G(d) (first entry), DFT-PCM (second entry), MP2/6-311++ G(d,p)//B3PW91/6-31G(d) (third entry), DFT-D (fourth entry). Bond lengths are in $\AA$. 

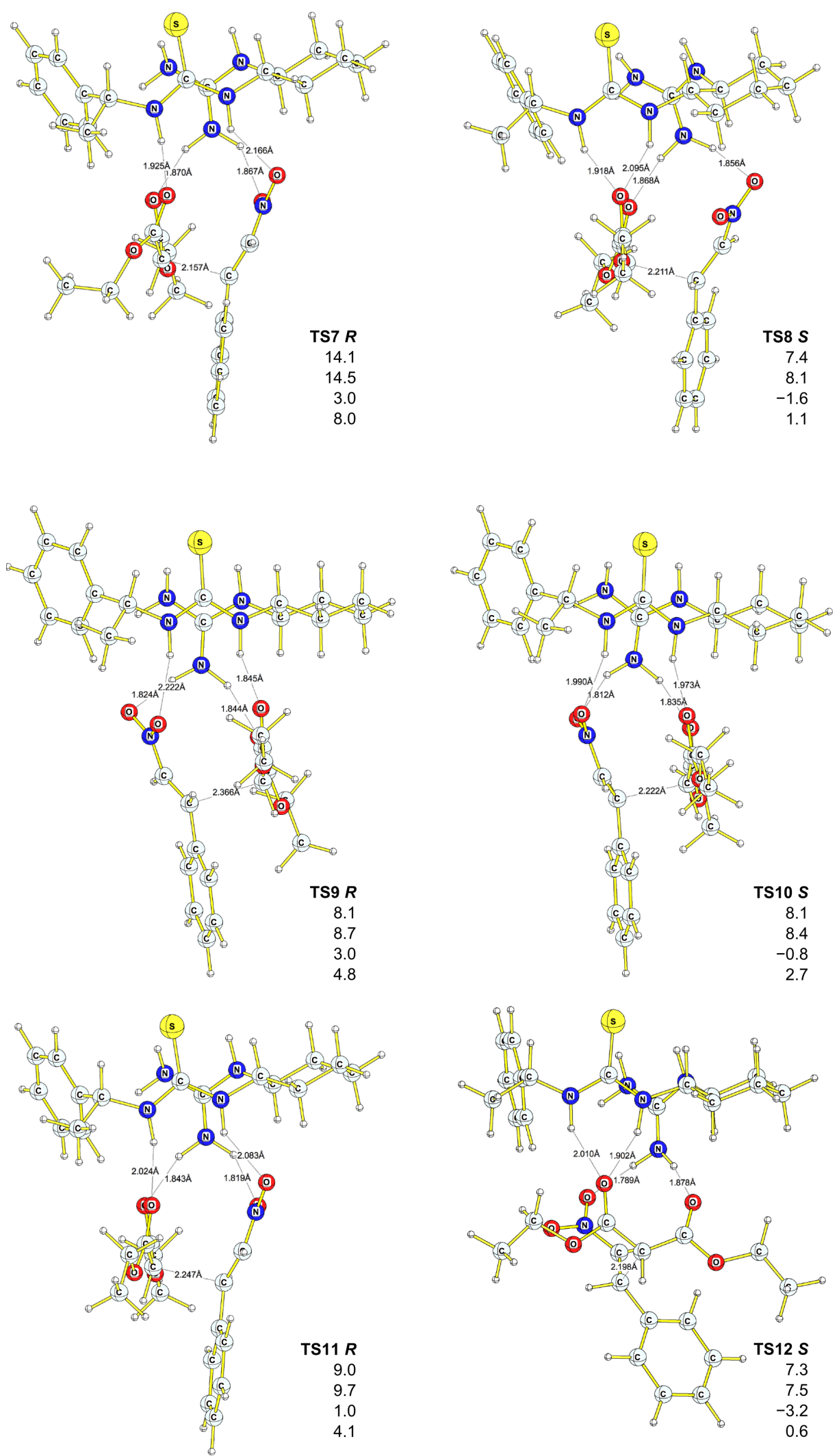

Figure 4: Geometries of transition states for $R$ and $S$ products. Relative energies (with respect to Init10) are in $\mathrm{kcal}^{\mathrm{k}} \cdot \mathrm{mol}^{-1}$, B3PW91/6-31G(d) (first entry), DFT-PCM (second entry), MP2/6-311++ G(d,p)//B3PW91/6-31G(d) (third entry), DFT-D (fourth entry). Bond lengths are in $\AA$. 
<smiles>CCCN1CCC=NN1C1CCCCC1NC(=S)NC(C)c1ccccc1</smiles>
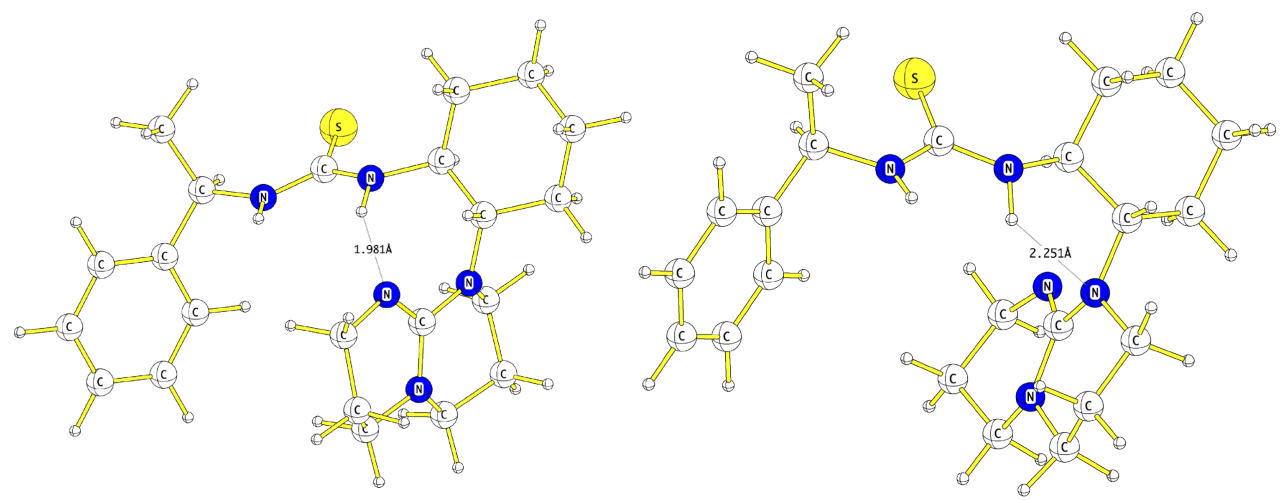

7-TABDa

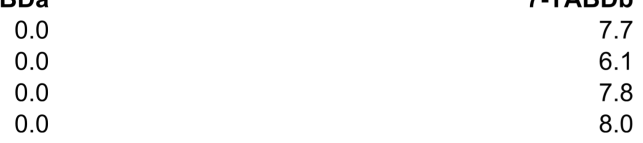

Figure 5: B3PW91/6-31G(d) (first entry), DFT-PCM (second entry), MP2/6-31G(d)//B3PW91/6-31G(d) (third entry) and DFT-D (fourth entry) optimized geometries of modified $7-\mathrm{TABD}$ catalyst. Energies are in $\mathrm{kcal} \cdot \mathrm{mol}^{-1}$, bond lengths are in $\AA$.

\begin{tabular}{|c|c|c|c|}
\hline & INIT & TS & FIN \\
\hline $13 R$ & $0.0(0.0)\{0.0\}[0.0]$ & $12.4(12.8)\{7.4\}[6.8]$ & $-2.4(-2.6)\{-13.2\}[-8.5]$ \\
\hline $14 S$ & $5.8(4.6)\{7.2\}[6.9]$ & $9.8(10.4)\{5.6\}[5.4]$ & $-3.4(-7.0)\{-9.4\}[-3.3]$ \\
\hline $15 R$ & $7.7(8.0)\{7.2\}[6.5]$ & $8.2(8.8)\{4.7\}[5.5]$ & $-2.4(-2.7)\{-12.5\}[-7.5]$ \\
\hline $16 R$ & $2.9(1.6)\{5.2\}[5.6]$ & $14.7(14.4)\{11.8\}[12.7]$ & $-2.2(-4.2)\{-11.4\}[-6.6]$ \\
\hline
\end{tabular}

semiempirical calculations suggest that the introduction of two $t$-Bu-groups into the 1,3- aryl positions would not improve the performance of the catalyst; the system remains too flexible. On the other hand, modification of the guanidine moiety by introducing a rigid aza-heterocycle (1,5,7-triazabicyclo[4.4.0]dec-5ene (TABD)) gave promising results.

For the modified 7-TABD catalyst, we found only two conformers that differ by ca. $6-8 \mathrm{kcal} \cdot \mathrm{mol}^{-1}$ (Figure 5). Assuming that the first part of the reaction pathway (coordination of either malonate or nitrostyrene to the catalyst, followed by addition of the third molecule) proceeds similarly to the pathway described above for the catalyst $7 /$ nitrostyrene/ malonate system (Scheme 5), we focused our attention on the second part of the reaction, the $\mathrm{C}-\mathrm{C}$ bond formation. We found four transition states, three of which lead to the $R$ product and only one to the $S$ equivalent (Figure 6).

Compared to the initial complexes INIT1-INIT12, the energy difference between the initial complexes INIT13-INIT16 is much higher (between 4.6 and $8.0 \mathrm{kcal} \cdot \mathrm{mol}^{-1}$, Table 3). Thus, in the case of the 7-TABD catalyst, interconversion between the initial complexes is less probable. Again, as in the case of catalyst 7 , the activation barriers seem to be overestimated at the gas-phase DFT and DFT-PCM levels, and underestimated with MP2/6-31G(d) and DFT-D corrections. Nevertheless, 

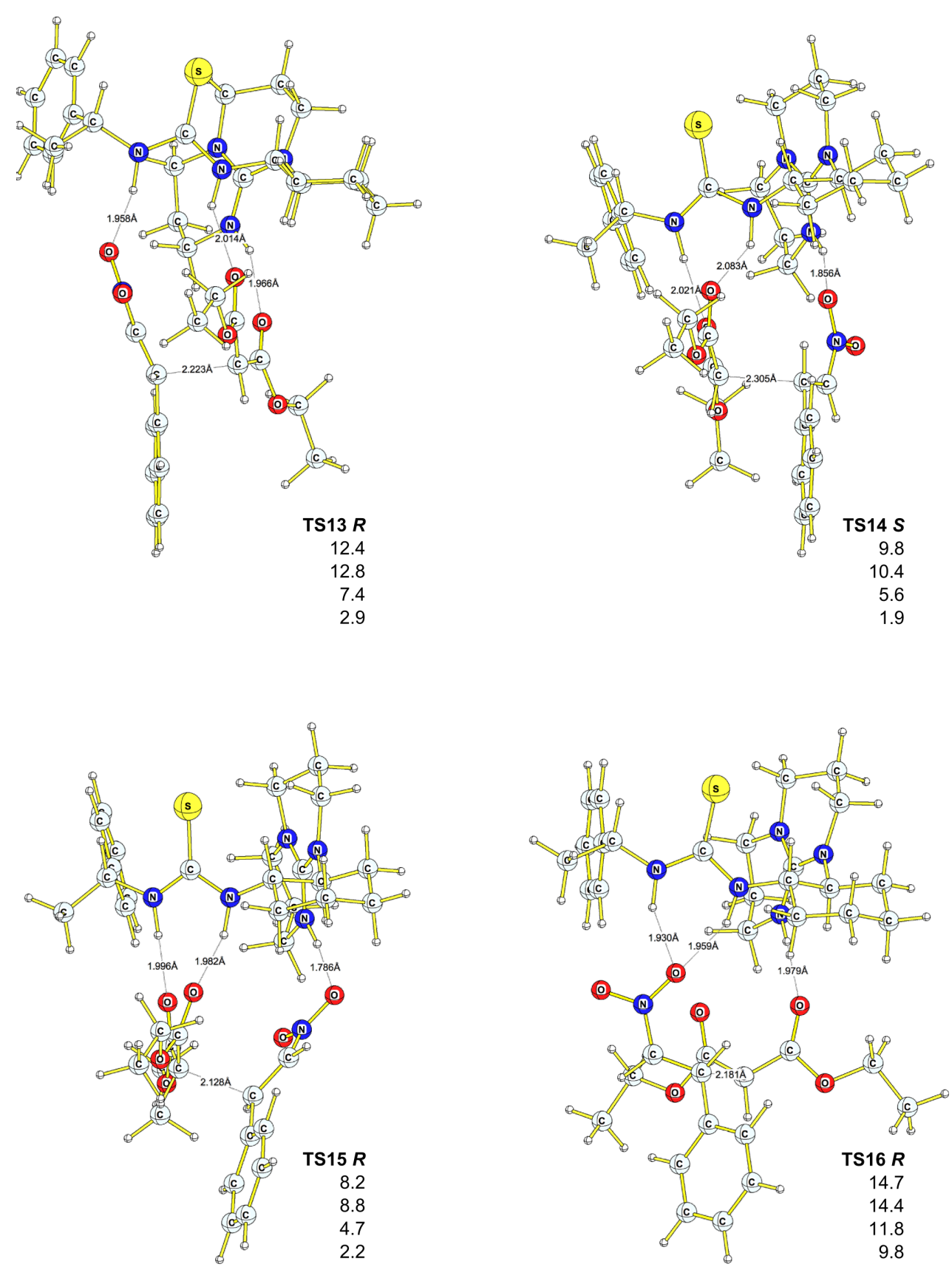

Figure 6: Geometries of transition states for $R$ and $S$ products with 7-TABD catalyst. Relative energies (to Init13) are in $\mathrm{kcal} \cdot \mathrm{mol}^{-1}$, B3PW91/ 6-31G(d) (first entry), DFT-PCM (second entry), MP2/6-31G(d)//B3PW91/6-31G(d) (third entry), DFT-D (fourth entry). Bond lengths are in A.

compared to catalyst 7 , the presence of the cyclic tri-aza moiety in 7-TABD increases the activation barriers. The reaction is calculated to favour the $R$ product, as both the initial complex and the TS leading to the $R$ product were found to be lower in energy than the $S$ equivalents.

\section{Conclusion}

In summary, we have demonstrated that the new guanidine derived chiral thiourea 7 can catalyse the asymmetric nitro-
Michael addition of diethyl malonate with trans- $\beta$-nitrostyrene, giving high yields (up to $96 \%$ ) but low enantioselectivities. Based on extensive computational studies, the low observed enantioselectivity of this nitro-Michael reaction can be explained in terms of the high activity and high conformational flexibility of the guanidine-thiourea catalyst, which lead to thermodynamic control of the reaction products. For further experimental studies, a modified more conformationally rigid catalyst is proposed. 
We would like to stress here that studies on systems of this size are influenced quite strongly by dispersion contributions [6066] and that standard DFT calculations should be supplemented by at least single-point MP2 energy corrections with an extensive, large basis set. The DFT-D method agrees very well with the MP2 results.

\section{Experimental}

General: Reagents obtained from commercial sources were used without further purification. Dichloromethane was dried by heating under reflux over $\mathrm{P}_{2} \mathrm{O}_{5}$ and by distillation. Diethylether was dried by heating under reflux over sodium/benzophenone and by distillation prior to use. Solvents for chromatography were distilled prior to use. TLC chromatography was performed on precoated aluminium silica gel ALUGRAM SIL G/UV254 plates (Macherey-Nagel GmbH \& Co.). Flash chromatography was performed on silica gel $60 \AA$ (Acros particle size: $0.035-0.070 \mathrm{~mm}$ ). NMR spectra were recorded on a Bruker Avance 300. FAB mass spectra were measured with a Micromass: ZabSpec. The enantiomeric excess of products was determined by chiral HPLC analysis in comparison with authentic racemic material. HPLC measurements were performed using Agilent 1200 Series equipment: vacuum degasser G1322-90010, quaternary pump G1311-90010, thermostated column compartment G1316-90010, diode array and multiple-wavelength detector SL G1315-90012, standard and preparative autosampler G1329-90020, and Agilent Chemstation for LC software.

(R)-(-)- $\alpha$-Methylbenzyl isothiocyanate (2): To a solution of $(R)$-1-phenylethylamine $(3.000 \mathrm{~g}, 3.151 \mathrm{~mL}, 24.76 \mathrm{mmol}$, 1.0 equiv) in anhydrous diethyl ether $(20 \mathrm{~mL})$, cooled to $0{ }^{\circ} \mathrm{C}$ and under a nitrogen atmosphere, carbon disulfide (12.065 g, $158.46 \mathrm{mmol}, 9.6 \mathrm{~mL}, 6.4$ equiv) and $N, N^{\prime}$-dicyclohexylcarbodiimide (5.109 g, $24.76 \mathrm{mmol}, 1.0$ equiv) were added. The reaction mixture was stirred overnight and allowed to warm to ambient temperature during this time. The precipitated $N, N^{\prime \prime}-$ dicyclohexylthiourea was filtered off, washed three times with diethyl ether and discarded. After evaporation of the filtrate, the residue was subjected to flash chromatography over silica gel (petrol ether/ethyl acetate 8:1) to yield $2(3.909 \mathrm{~g}, 23.94 \mathrm{mmol}$, 97\%) as a colourless oil. $[\alpha]_{\mathrm{D}}{ }^{25}-4.3$ (c 1.0, acetone); ${ }^{1} \mathrm{H}$ NMR $\left(300 \mathrm{MHz}, \mathrm{CDCl}_{3}\right) \delta 1.68(\mathrm{~d}, J=6.7 \mathrm{~Hz}, 3 \mathrm{H}), 4.92(\mathrm{q}, J=$ $6.7 \mathrm{~Hz}, 1 \mathrm{H}), 7.27-7.50(\mathrm{~m}, 5 \mathrm{H}) \mathrm{ppm} ;{ }^{13} \mathrm{C} \mathrm{NMR}(75 \mathrm{MHz}$, $\left.\mathrm{CDCl}_{3}\right) \delta 24.96,57.00,125.39,128.18,128.88,140.11 \mathrm{ppm}$.

Primary amine-thiourea 3: To a solution of $(S, S)-1,2-$ diaminocyclohexane (1) (1.273 g, $11.15 \mathrm{mmol}, 1.0$ equiv) in anhydrous dichloromethane $(100 \mathrm{~mL})$, at ambient temperature and under a nitrogen atmosphere, a solution of $2(1.820 \mathrm{~g}$, $11.15 \mathrm{mmol}, 1.0$ equiv) in anhydrous dichloromethane $(60 \mathrm{~mL})$ was added dropwise over $7 \mathrm{~h}$. The solvent was evaporated and flash chromatography on silica gel (first with ethyl acetate to elute impurities, then with ethyl acetate/ethanol 8:1) gave 3 $(1.731 \mathrm{~g}, 6.24 \mathrm{mmol}, 56 \%)$ as a colourless solid. $[\alpha]_{\mathrm{D}}{ }^{25}-85(c$ 1.0, chloroform); ${ }^{1} \mathrm{H}$ NMR (300 MHz, DMSO- $\left.d_{6}\right) \delta 0.90-1.30$ (m, 4H), 1.39 (d, $J=7.0 \mathrm{~Hz}, 3 \mathrm{H}), 1.49-1.67(\mathrm{~m}, 2 \mathrm{H}), 1.72-1.84$ (m, 1H), 1.88-2.02 (m, 1H), 2.40-2.46 (m, 1H), 5.34-5.52 (m, 1H), 7.14-7.42 (m, 5H) ppm; ${ }^{13} \mathrm{C}$ NMR (75 MHz, DMSO- $\left.d_{6}\right) \delta$ 22.81, 24.71, 24.84, 31.82, 34.69, 52.63, 54.53, 59.73, 126.42, $126.95,128.59,144.85,182.03$ ppm; MS-FAB $(\mathrm{m} / \mathrm{z}): 181,262$, $278[\mathrm{M}+\mathrm{H}]^{+}, 289,391$.

Compound 5: A solution of $\mathbf{3}$ ( $0.100 \mathrm{~g}, 0.36 \mathrm{mmol}, 1.0$ equiv), 1,3-bis(tert-butoxycarbonyl)-2-(trifluoromethylsulfonyl)-guanidine $(0.141 \mathrm{~g}, 0.36 \mathrm{mmol}, 1.0$ equiv) and triethylamine ( $0.036 \mathrm{~g}, 0.049 \mathrm{~mL}, 0.36 \mathrm{mmol}, 1.0$ equiv) in dichloromethane $(5 \mathrm{~mL})$ was stirred for $24 \mathrm{~h}$ at ambient temperature and evaporated. The residue was purified by flash chromatography over silica gel (petrol ether/ethyl acetate $6: 1)$ to obtain $5(0.182 \mathrm{~g}$, $0.35 \mathrm{mmol}, 98 \%)$ as a colourless solid. ${ }^{1} \mathrm{H}$ NMR $(300 \mathrm{MHz}$, DMSO- $\left.d_{6}\right) \delta 1.17-1.36(\mathrm{~m}, 4 \mathrm{H}) 1.41(\mathrm{~s}, 3 \mathrm{H}), 1.45(\mathrm{~s}, 9 \mathrm{H}), 1.47$ (s, 9H), 1.51-1.60 (m, 2H), 1.63-1.79 (m, 1H), 1.89-2.07 (m, $1 \mathrm{H}), 2.60-2.68(\mathrm{~m}, 1 \mathrm{H}), 3.83-3.98(\mathrm{~m}, 1 \mathrm{H}), 4.15-4.32(\mathrm{~m}, 1 \mathrm{H})$, $7.16-7.39(\mathrm{~m}, 5 \mathrm{H}), 7.77(\mathrm{~m}, 1 \mathrm{H}), 8.33(\mathrm{~d}, J=7.7 \mathrm{~Hz}, 1 \mathrm{H}), 9.02$ $(\mathrm{m}, 1 \mathrm{H}), 11.56(\mathrm{~m}, 1 \mathrm{H}) \mathrm{ppm}$; MS-FAB $(\mathrm{m} / \mathrm{z}): 193,199,205$, $225,260,287,320[\mathrm{M}-2 \mathrm{Boc}+\mathrm{H}]^{+}, 420[\mathrm{M}-\mathrm{Boc}+\mathrm{H}]^{+}, 521$ $[\mathrm{M}+\mathrm{H}]^{+}$.

Compound 6: A solution of 5 ( $0.160 \mathrm{~g}, 0.31 \mathrm{mmol}, 1.0$ equiv) in dichloromethane $(3 \mathrm{~mL})$ was treated with trifluoroacetic acid (1.535 g, $1.0 \mathrm{~mL}, 13.46 \mathrm{mmol}, 43.4$ equiv) at ambient temperature for $7 \mathrm{~h}$. The solvents were evaporated and the residue was purified by column chromatography over silica gel (dichloromethane/methanol 95:5) to yield 6 (0.112 g, $0.26 \mathrm{mmol}, 85 \%)$ as a colourless, hygroscopic solid. $[\alpha]_{\mathrm{D}}{ }^{25}-13.62(c \quad 0.1$, ethanol); ${ }^{1} \mathrm{H}$ NMR (300 MHz, DMSO- $\left.d_{6}\right) \delta 1.05-1.35(\mathrm{~m}, 4 \mathrm{H})$, $1.41(\mathrm{~d}, J=6.2 \mathrm{~Hz}, 3 \mathrm{H}), 1.51-1.74(\mathrm{~m}, 2 \mathrm{H}), 1.79-1.93(\mathrm{~m}, 1 \mathrm{H})$, 1.93-2.19 (m, 1H), 2.56-2.68 (m, 1H), 3.37-3.47 (m, 1H), 4.11 $(\mathrm{d}, J=6.2 \mathrm{~Hz}, 1 \mathrm{H}), 6.65-6.97(\mathrm{~m}, 2 \mathrm{H}), 7.12-7.58(\mathrm{~m}, 9 \mathrm{H})$, 7.91-8.06 (m, 1H) ppm; ${ }^{13} \mathrm{C}$ NMR (75 MHz, DMSO-d $\left.d_{6}\right) \delta$ $14.15,20.72,22.39,23.54,30.92,31.45,53.55,59.72,115.64$, 118.76, 125.52, 126.03, 126.23, 128.33, 144.46, 156.41, 158.44, 170.34 ppm. MS-FAB (m/z): 107, 120, 124, 136, 154, 199, 286, 289, 307, $320\left[\mathrm{M}-\mathrm{CF}_{3} \mathrm{COO}^{-}\right]^{+}, 376,391$; Anal. calcd: $\mathrm{C}$, 49.87; H, 6.05; N, 16.16; S, 7.40; found: C, 47.41; H, 5.37; N, 13.98; S, 7.26.

Guanidine-thiourea 7: Compound $6(0.115 \mathrm{~g}, 0.27 \mathrm{mmol}$, 1.0 equiv) was treated with Amberlyst A26 $\left(\mathrm{OH}^{-}\right.$form $)$(1.885 g) in methanol $(20 \mathrm{~mL})$ for $15 \mathrm{~min}$. The ion exchanger was filtered off over Celite and the filtrate was evaporated to yield 7 
$(0.081 \mathrm{~g}, 0.25 \mathrm{mmol}, 93 \%)$ as a white solid. $[\alpha]_{\mathrm{D}}{ }^{25}+19.92(c$ 0.1 , methanol); ${ }^{1} \mathrm{H}$ NMR (300 MHz, DMSO- $\left.d_{6}\right) \delta 0.97-1.44$ (m, 4H), 1.44-1.58 (m, 3H), 1.58-1.80 (m, 2H), 1.81-1.94 (m, $1 \mathrm{H}), 1.94-2.37$ (m, 1H), 2.48-2.57 (m, 1H), 3.44-3.58 (m, 1H), 3.71-3.98 (m, 1H), 4.60 (br s, 4H), 7.22-7.50 (m, 5H) ppm; MS-FAB $(\mathrm{m} / \mathrm{z}): 107,120,136,154,176,199,286,307,320$ $[\mathrm{M}+\mathrm{H}]^{+}, 376,391$.

Henry reaction of 3-phenylpropionaldehyde (8) and nitromethane (9), mediated by 7: 4-Phenyl-1-nitro-2-butanol (10): A solution of 7 (0.1 equiv), 3-phenylpropionaldehyde (1.0 equiv) and nitromethane (3.0 equiv) in toluene ([aldehyde] $=0.11 \mathrm{M}$ ) was stirred for the appropriate time and at the corresponding temperature. The organic phase was diluted with toluene, washed with saturated aqueous ammonium chloride solution, and dried over magnesium sulfate. Product 10 was isolated by preparative thin-layer chromatography over silica gel. ${ }^{1} \mathrm{H}$ NMR $\left(300 \mathrm{MHz}, \mathrm{DMSO}-d_{6}\right) \delta 1.58-1.83(\mathrm{~m}, 2 \mathrm{H})$, 2.55-2.82 (m, 2H), 4.05-4.17 (m, 1H), 4.39 (dd, $J=9.3 \mathrm{~Hz}, J=$ $12.2 \mathrm{~Hz}, 1 \mathrm{H}), 4.71(\mathrm{dd}, J=3.0 \mathrm{~Hz}, J=12.2 \mathrm{~Hz}, 1 \mathrm{H}), 5.48$ (d, $J=6.4 \mathrm{~Hz}, 1 \mathrm{H}), 7.10-7.36(\mathrm{~m}, 5 \mathrm{H}) \mathrm{ppm} ;{ }^{13} \mathrm{C} \mathrm{NMR}(75 \mathrm{MHz}$, DMSO- $\left.d_{6}\right): \delta 30.62,35.36,67.21,81.34,125.56,128.09$, 141.33 ppm; MS-FAB $(\mathrm{m} / \mathrm{z}): 107,120,124,137,149$ [M $\left.\mathrm{NO}_{2}^{-}\right]^{+}, 154,167,289,307,391$.

Michael addition of 2,4-pentanedione (12) and trans- $\beta$ nitrostyrene (11), mediated by 7: 3-(2-Nitro-1-phenylethyl)pentane-2,4-dione (13): A solution of 7 (8.99 mg, $28.14 \mu \mathrm{mol}$, 0.2 equiv) and acetylacetone $(140.87 \mathrm{mg}, 1407.00 \mu \mathrm{mol}$, 10.0 equiv) was stirred for $5 \mathrm{~min}$ at ambient temperature. trans$\beta$-Nitrostyrene was added and the mixture was stirred for $5 \mathrm{~d}$ at ambient temperature. The solution is diluted with ethyl acetate $(10 \mathrm{~mL})$, washed with aqueous $20 \%$ potassium hydrogen sulfate solution $(3 \mathrm{~mL})$ and brine $(3 \mathrm{~mL})$. After drying over magnesium sulfate, the organic phase was evaporated and purified by column chromatography over silica gel (petrol ether/ethyl acetate 2:1) to yield $13(19.00 \mathrm{mg}, 76.23 \mu \mathrm{mol}, 54 \%) .{ }^{1} \mathrm{H}$ NMR $\left(300 \mathrm{MHz}, \mathrm{CDCl}_{3}\right) \delta 1.87(\mathrm{~s}, 3 \mathrm{H}), 2.21(\mathrm{~s}, 3 \mathrm{H}), 4.12-4.23(\mathrm{~m}$, $1 \mathrm{H}), 4.30(\mathrm{~d}, J=10.7 \mathrm{~Hz}, 1 \mathrm{H}), 4.48-4.64(\mathrm{~m}, 2 \mathrm{H}), 7.07-7.33$ $(\mathrm{m}, 5 \mathrm{H}) \mathrm{ppm} ;{ }^{13} \mathrm{C} \mathrm{NMR}\left(75 \mathrm{MHz}, \mathrm{CDCl}_{3}\right) \delta 29.54,30.38$, $42.74,70.62,78.11,127.90,128.48,129.27,135.97,200.98$, $201.70 \mathrm{ppm}$.

Michael addition of diethylmalonate (14) and trans- $\beta$ nitrostyrene (11), mediated by 7: Diethyl 2-(2-nitro-1phenylethyl)malonate (15): A solution of trans- $\beta$-nitrostyrene (1.0 equiv), diethyl malonate (5.0 equiv) and 7 ( 0.2 equiv) in the desired solvent $([$ trans- $\beta$-nitro-styrene $]=0.1 \mathrm{M})$ is stirred at a certain temperature and for the appropriate time. The reaction is quenched with concentrated aqueous hydrochloric acid/methanol 1:10, and subjected to flash chromatography over silica gel (petrol ether/ethyl acetate 6:1). ${ }^{1} \mathrm{H}$ NMR $\left(300 \mathrm{MHz}, \mathrm{CDCl}_{3}\right) \delta$ $0.98(2 \mathrm{t}, J=7.2 \mathrm{~Hz}, 3 \mathrm{H}), 1.20(2 \mathrm{t}, J=7.2 \mathrm{~Hz}, 3 \mathrm{H}), 3.76(2 \mathrm{~d}, J=$ $9.4 \mathrm{~Hz}, 1 \mathrm{H}), 3.94(2 \mathrm{q}, J=7.2 \mathrm{~Hz}, 2 \mathrm{H}), 4.10-4.24(\mathrm{~m}, 3 \mathrm{H})$, 4.73-4.92 (m, 2H), 7.11-7.33 (m, 5H) ppm; ${ }^{13} \mathrm{C}$ NMR $\left(150.8 \mathrm{MHz}, \mathrm{CDCl}_{3}\right) \delta 13.66,13.90,42.89,54.88,61.82,62.10$, $77.59,127.96,128.28,128.86,136.14,166.76,167.40 \mathrm{ppm}$.

\section{Computational methods}

Geometries of all structures were fully optimized at the B3PW91 [67-69] level of theory by using the 6-31G(d) [70-80] basis set within the Gaussian 03 program package [81]. Stationary points were confirmed to be minima or transition states by calculating the normal vibrations within the harmonic approximation. The reaction pathways along both directions from the transition structures were followed by the IRC method $[82,83]$. DFT-computed energies were corrected for zero-point vibrational energies (ZPVE). Single-point self-consistent reaction field (SCRF) [84] calculations were used to calculate the solvation energies in tetrahydrofuran within the PCM model (denoted as DFT-PCM). Single-point MP2 [66] energies with DZ and TZ basis sets were computed at the B3PW91 optimized geometries (denoted as MP2/6-31G(d)//B3PW91/6-31G(d) and MP2/6-311+G(d,p)//B3PW91/6-31G(d), respectively). Singlepoint DFT calculations with empirical van der Waals corrections [63] were performed with the ORCA program [85].

\section{Supporting Information}

The Supporting Information File features data from DFT computations (computed absolute energies (Hartree) and zero-point vibrational energies (ZPVE, $\left.\mathrm{kcal} \cdot \mathrm{mol}^{-1}\right)$ at different levels of theory) as well as the respective GAUSSIAN archive entries.

\section{Supporting Information File 1}

Detailed information about the DFT calculations

[http://www.beilstein-journals.org/bjoc/content/ supplementary/1860-5397-8-168-S1.pdf]

\section{Acknowledgements}

The authors gratefully acknowledge generous financial support from the Deutsche Forschungsgemeinschaft (SPP 1179 "Organocatalysis") and the generous amount of computational time from HLRBII (LRZ).

\section{References}

1. Ma, J.-A.; Cahard, D. Angew. Chem., Int. Ed. 2004, 43, 4566-4583. doi:10.1002/anie.200300635

2. Shibasaki, M.; Yoshikawa, N. Chem. Rev. 2002, 102, 2187-2209. doi:10.1021/cr010297z 
3. Gröger, H. Chem.-Eur. J. 2001, 7, 5246-5251. doi:10.1002/1521-3765(20011217)7:24<5246::AID-CHEM5246>3.0.C O;2-O

4. Shibasaki, M.; Sasai, H.; Arai, T. Angew. Chem., Int. Ed. Engl. 1997, 36, 1236-1256. doi:10.1002/anie.199712361

5. Dalko, P. I.; Moisan, L. Angew. Chem., Int. Ed. 2001, 40, 3726-3748. doi:10.1002/1521-3773(20011015)40:20<3726::AID-ANIE3726>3.0.CO ;2-D

6. Berkessel, A.; Groeger, H. Asymmetric Organocatalysis - From Biomimetic Concepts to Applications in Asymmetric Synthesis; Wiley-VCH: Weinheim, 2004.

7. Pihko, P. M. Angew. Chem., Int. Ed. 2004, 43, 2062-2064. doi:10.1002/anie.200301732

8. Seayad, J.; List, B. Org. Biomol. Chem. 2005, 3, 719-724. doi:10.1039/b415217b

9. Schreiner, P. R. Chem. Soc. Rev. 2003, 32, 289-296. doi:10.1039/b107298f

10. Takemoto, Y. Org. Biomol. Chem. 2005, 3, 4299-4306. doi:10.1039/b511216h

11. Taylor, M. S.; Jacobsen, E. N. Angew. Chem., Int. Ed. 2006, 45, 1520-1543. doi:10.1002/anie.200503132

12. Connon, S. J. Chem.-Eur. J. 2006, 12, 5418-5427. doi:10.1002/chem.200501076

13. Doyle, A. G.; Jacobsen, E. N. Chem. Rev. 2007, 107, 5713-5743. doi:10.1021/cr068373r

14. Okino, T.; Hoashi, Y.; Takemoto, Y. J. Am. Chem. Soc. 2003, 125, 12672-12673. doi:10.1021/ja036972z

15. Okino, T.; Nakamura, S.; Furukawa, T.; Takemoto, Y. Org. Lett. 2004, 6, 625-627. doi:10.1021/ol0364531

16. Maher, D. J.; Connon, S. J. Tetrahedron Lett. 2004, 45, 1301-1305. doi:10.1016/j.tetlet.2003.11.062

17. Fuerst, D. E.; Jacobsen, E. N. J. Am. Chem. Soc. 2005, 127, 8964-8965. doi:10.1021/ja052511x

18. Yoon, T. P.; Jacobsen, E. N. Angew. Chem., Int. Ed. 2005, 44, 466-468. doi:10.1002/anie.200461814

19. Li, B.-J.; Jiang, L.; Liu, M.; Chen, Y.-C.; Ding, L.-S.; Wu, Y. Synlett 2005, 603-606. doi:10.1055/s-2005-863710

20. Hoashi, Y.; Okino, T.; Takemoto, Y. Angew. Chem., Int. Ed. 2005, 44, 4032-4035. doi:10.1002/anie.200500459

21. Vakulya, B.; Varga, S.; Csampai, A.; Soos, T. Org. Lett. 2005, 7, 1967-1969. doi:10.1021/ol050431s

22. Okino, T.; Hoashi, Y.; Furukawa, T.; Xu, X.; Takemoto, Y. J. Am. Chem. Soc. 2005, 127, 119-125. doi:10.1021/ja044370p

23. McCooey, S. H.; Connon, S. J. Angew. Chem., Int. Ed. 2005, 44 6367-6370. doi:10.1002/anie.200501721

24. Berkessel, A.; Cleemann, F.; Mukherjee, S.; Müller, T. N.; Lex, J. Angew. Chem., Int. Ed. 2005, 44, 807-811. doi:10.1002/anie.200461442

25. Berkessel, A.; Cleemann, F.; Mukherjee, S. Angew. Chem., Int. Ed. 2005, 44, 7466-7469. doi:10.1002/anie.200502003

26. Berkessel, A.; Mukherjee, S.; Cleemann, F.; Müller, T. N.; Lex, J. Chem. Commun. 2005, 1898-1900. doi:10.1039/b418666d

27. Wang, J.; Li, H.; Yu, X.; Zu, L.; Wang, W. Org. Lett. 2005, 7, 4293-4296. doi:10.1021/ol051822+

28. Inokuma, T.; Hoashi, Y.; Takemoto, Y. J. Am. Chem. Soc. 2006, 128, 9413-9419. doi:10.1021/ja061364f

29. Xu, X.; Furukawa, T.; Okino, T.; Miyabe, H.; Takemoto, Y. Chem.-Eur. J. 2006, 12, 466-476. doi:10.1002/chem.200500735
30. Marcelli, T.; van der Haas, R. N. S.; van Maarseveen, J. H.; Hiemstra, H. Angew. Chem., Int. Ed. 2006, 118, 943-945. doi:10.1002/ange.200503724

31. Cao, Y.-J.; Lu, H.-H.; Lai, Y.-Y.; Lu, L.-Q.; Xiao, W.-J. Synthesis 2006, 3795-3800. doi:10.1055/s-2006-950339

32. Cao, C.-L.; Ye, M.-C.; Sun, X.-L.; Tang, Y. Org. Lett. 2006, 8, 2901-2904. doi:10.1021/ol060481c

33. Zuend, S. J.; Jacobsen, E. N. J. Am. Chem. Soc. 2007, 129, 15872-15883. doi:10.1021/ja0735352

34. Wang, B.; Wu, F.; Wang, Y.; Liu, X.; Deng, L. J. Am. Chem. Soc. 2007, 129, 768-769. doi:10.1021/ja0670409

35. Dinér, P.; Nielsen, M.; Bertelsen, S.; Niess, B.; Jørgensen, K. A Chem. Commun. 2007, 3646-3648. doi:10.1039/b707844g

36. Tsogoeva, S. B.; Wei, S. Chem. Commun. 2006, 1451-1453. doi:10.1039/b517937h

37. Huang, H.; Jacobsen, E. N. J. Am. Chem. Soc. 2006, 128, 7170-7171. doi:10.1021/ja0620890

38. Yalalov, D. A.; Tsogoeva, S. B.; Schmatz, S. Adv. Synth. Catal. 2006, 348, 826-832. doi:10.1002/adsc.200505443

39. Lalonde, M. P.; Chen, Y.; Jacobsen, E. N. Angew. Chem., Int. Ed. 2006, 45, 6366-6370. doi:10.1002/anie.200602221

40. Wei, S.; Yalalov, D. A.; Tsogoeva, S. B.; Schmatz, S. Catal. Today 2007, 121, 151-157. doi:10.1016/j.cattod.2006.11.018

41. Liu, K.; Cui, H.-F.; Nie, J.; Dong, K.-Y.; Li, X.-J.; Ma, J.-A. Org. Lett. 2007, 9, 923-925. doi:10.1021/ol0701666

42. Yalalov, D. A.; Tsogoeva, S. B.; Shubina, T. E.; Martynova, I. M.; Clark, T. Angew. Chem., Int. Ed. 2008, 47, 6624-6628. doi:10.1002/anie.200800849

43. Tsogoeva, S. B.; Hateley, M. J.; Yalalov, D. A.; Meindl, K.; Weckbecker, C.; Huthmacher, K. Bioorg. Med. Chem. 2005, 13, 5680-5685. doi:10.1016/j.bmc.2005.05.014

44. Tsogoeva, S. B.; Yalalov, D. A.; Hateley, M. J.; Weckbecker, C.; Huthmacher, K. Eur. J. Org. Chem. 2005, 4995-5000. doi:10.1002/ejoc.200500420

45. Berner, O. M.; Tedeschi, L.; Enders, D. Eur. J. Org. Chem. 2002 1877-1894. doi:10.1002/1099-0690(200206)2002:12<1877::AID-EJOC1877>3.0.C $\mathrm{O} ; 2-\mathrm{U}$

46. Tsogoeva, S. B. Eur. J. Org. Chem. 2007, 1701-1716. doi:10.1002/ejoc. 200600653

47. Almasi, D.; Alonso, D. A.; Nájera, C. Tetrahedron: Asymmetry 2007, 18, 299-365. doi:10.1016/j.tetasy.2007.01.023

48. Armarego, W. L. F.; Chai, C. L. L. Purification of Laboratory Chemicals, 5th ed.; Elsevier Science: Burlington, MA, 2003

49. Ishikawa, T.; Kumamoto, T. Synthesis 2006, 737-752. doi:10.1055/s-2006-926325

50. Sohtome, Y.; Hashimoto, Y.; Nagasawa, K. Adv. Synth. Catal. 2005, 347, 1643-1648. doi:10.1002/adsc.200505148

51. Sohtome, Y.; Takemura, N.; Iguchi, T.; Hashimoto, Y.; Nagasawa, K. Synlett 2006, 144-146. doi:10.1055/s-2005-922770

52. Sohtome, Y.; Hashimoto, Y.; Nagasawa, K. Eur. J. Org. Chem. 2006, 2894-2897. doi:10.1002/ejoc.200600307

53. Sohtome, Y.; Takemura, N.; Takada, K.; Takagi, R.; Iguchi, T.; Nagasawa, K. Chem.-Asian J. 2007, 2, 1150-1160. doi:10.1002/asia.200700145

54. Feichtinger, K.; Zapf, C.; Sings, H. L.; Goodman, M. J. Org. Chem. 1998, 63, 3804-3805. doi:10.1021/jo980425s

55. Dodd, D. S.; Wallace, O. B. Tetrahedron Lett. 1998, 39, 5701-5704. doi:10.1016/S0040-4039(98)01197-6 
56. Ley, S. V.; Massi, A. J. Chem. Soc., Perkin Trans. 1 2000, 3645-3654. doi:10.1039/B003129L

57. Hamza, A.; Schubert, G.; Soos, T.; Pápai, I. J. Am. Chem. Soc. 2006, 128, 13151-13160. doi:10.1021/ja063201x

58. VAMP, v9.0; Computer-Chemie-Centrum, Universität Erlangen-Nürnberg: Erlangen, 2005.

59. Schenker, S.; Schneider, C.; Tsogoeva, S. B.; Clark, T. J. Chem. Theory Comput. 2011, 7, 3586-3595. doi:10.1021/ct2002013

60. He, X.; Fusti-Molnar, L.; Cui, G.; Merz, K. M., Jr. J. Phys. Chem. B 2009, 113, 5290. doi:10.1021/jp8106952

61. Schreiner, P. R.; Chernish, L. V.; Gunchenko, P. A.; Tikhonchuk, E. Y.; Hausmann, H.; Serafin, M.; Schlecht, S.; Dahl, J. E. P.; Carlson, R. M. K.; Fokin, A. A. Nature 2011, 477, 308-311. doi:10.1038/nature10367

62. Grimme, S.; Schreiner, P. R. Angew. Chem., Int. Ed. 2011, 50 , 12639-12642. doi:10.1002/anie.201103615

63. Grimme, S. J. Comput. Chem. 2006, 27, 1787-1799. doi:10.1002/jcc.20495

64. Sieffert, N.; Bühl, M. Inorg. Chem. 2009, 48, 4622-4624. doi:10.1021/ic900347e

65. Seebach, D.; Grošelj, U.; Schweizer, W. B.; Grimme, S.; Mück-Lichtenfeld, C. Helv. Chim. Acta 2010, 93, 1-16. doi:10.1002/hlca.200900376

66. Møller, C.; Plesset, M. S. Phys. Rev. 1934, 46, 618-622. doi:10.1103/PhysRev.46.618

67. Becke, A. D. J. Chem. Phys. 1993, 98, 5648-5652. doi:10.1063/1.464913

68. Perdew, J. P.; Burke, K.; Wang, Y. Phys. Rev. B 1996, 54 16533-16539. doi:10.1103/PhysRevB.54.16533

69. Perdew, J. P.; Chevary, J. A.; Vosko, S. H.; Jackson, K. A.; Pederson, M. R.; Singh, D. J.; Fiolhais, C. Phys. Rev. B 1992, 46, 6671-6687. doi:10.1103/PhysRevB.46.6671

70. Ditchfield, R.; Hehre, W. J.; Pople, J. A. J. Chem. Phys. 1971, 54, 724. doi:10.1063/1.1674902

71. Hariharan, P. C.; Pople, J. A. Theor. Chim. Acta 1973, 28, 213-222. doi:10.1007/BF00533485

72. Hariharan, P. C.; Pople, J. A. Mol. Phys. 1974, 27, 209-214. doi:10.1080/00268977400100171

73. Hehre, W. J.; Ditchfield, R.; Pople, J. A. J. Chem. Phys. 1972, 56, 2257. doi:10.1063/1.1677527

74. Gordon, M. S. Chem. Phys. Lett. 1980, 76, 163-168. doi:10.1016/0009-2614(80)80628-2

75. Blaudeau, J.-P.; McGrath, M. P.; Curtiss, L. A.; Radom, L. J. Chem. Phys. 1997, 107, 5016. doi:10.1063/1.474865

76. Francl, M. M.; Pietro, W. J.; Hehre, W. J.; Binkley, J. S.; Gordon, M. S.; DeFrees, D. J.; Pople, J. A. J. Chem. Phys. 1982, 77, 3654. doi:10.1063/1.444267

77. Binning, R. C., Jr.; Curtiss, L. A. J. Comput. Chem. 1990, 11, 1206-1216. doi:10.1002/jcc.540111013

78. Rassolov, V. A.; Pople, J. A.; Ratner, M. A.; Windus, T. L. J. Chem. Phys. 1998, 109, 1223. doi:10.1063/1.476673

79. Rassolov, V. A.; Ratner, M. A.; Pople, J. A.; Redfern, P. C.; Curtiss, L. A. J. Comput. Chem. 2001, 22, 976-984. doi:10.1002/jcc.1058

80. Frisch, M. J.; Pople, J. A.; Binkley, J. S. J. Chem. Phys. 1984, 80, 3265. doi:10.1063/1.447079

81. Gaussian 03, Revision C.02; Gaussian, Inc.: Wallingford CT, 2004.

82. Gonzalez, C.; Schlegel, H. B. J. Phys. Chem. 1990, 94, 5523-5527. doi:10.1021/j100377a021
83. Gonzalez, C.; Schlegel, H. B. J. Chem. Phys. 1989, 90, 2154. doi:10.1063/1.456010

84. Foresman, J. B.; Keith, T. A.; Wiberg, K. B.; Snoonian, J.; Frisch, M. J. J. Phys. Chem. 1996, 100, 16098-16104. doi:10.1021/jp960488j

85. Orca, an ab initio, DFT and semiempirical SCF-MO package. http://www.mpibac.mpg.de/bac/index_en.php (accessed June 30, 2012).

\section{License and Terms}

This is an Open Access article under the terms of the Creative Commons Attribution License

(http://creativecommons.org/licenses/by/2.0), which permits unrestricted use, distribution, and reproduction in any medium, provided the original work is properly cited.

The license is subject to the Beilstein Journal of Organic Chemistry terms and conditions:

(http://www.beilstein-journals.org/bjoc)

The definitive version of this article is the electronic one which can be found at: doi:10.3762/bjoc. 8.168 